\title{
EN LA BÚSQUEDA DE SÍ MISMAS: UNA CONSTRUCCIÓN POLITITICA
}

LILIANA PATRICIA TORRES VICTORIA*

\section{RESUMEN}

\begin{abstract}
Este escrito pretende dar cuenta del proceso de constitución de sujetos sociales y políticos desde la experiencia de mujeres que se desempeñan como consejeras de familia en el sector Marroquín II del Distrito de Aguablanca. Los argumentos que se presentan han sido construídos a partir de una investigación ${ }^{1}$ realizada sobre el tema durante el año 2003, la cual permitió identificar en el proceso, cómo las mujeres construyen conciencia sobre su entorno, logran transformarlo y generan nuevas formas de hacer política.
\end{abstract}

Palabras clave: Sujeto social - Sujeto político

\begin{abstract}
This writing seeks to give bill of the process of constitution of individual social and political from the experience of women that act as family consultants in the sector Marroquin II of the District of Aguablanca. The arguments that are presented have been built starting from an investigation carried out on the topic during the years 2003, which allowed to identify in the process, how the women build conscience on their environment, they are able to transform it and generate new forms of making political.
\end{abstract}

Key words: Individual Social-Individual Political

\section{PRESENTACIÓN}

$\mathbf{H}$ ace más de 15 años varias mujeres de la Comuna 14, con el apoyo de personas voluntariamente asociadas, especialmente mujeres, inician una serie de reuniones de reflexión sobre sus condiciones y calidad de vida personal y familiar. Dichas reflexiones se centraban en las posibilidades y limitaciones que tenían las mujeres habitantes del sector y por ende sus familias, para poder brindar satisfacción adecuada a sus necesidades, a través de opciones de empleo, educación, fortalecimiento espiritual y crecimiento humano, en las que sus potenciales aspiraciones, ilusiones, sueños de un futuro mejor, de una comunidad sana y segura para el

* Docente, Escuela de Trabajo Social y Desarrollo Humano. Universidad del Valle.

${ }^{1}$ La investigación se titula "La constitución de sujetos sociales y políticos en experiencias sociales de mujeres del sector de Marroquín II del Distrito de Aguablanca. 
crecimiento de sus hijos y unos ideales de convivencia pacífica y relaciones familiares armoniosas delinearon los parámetros de las actividades a seguir y las propuestas de trabajo.

Estas mujeres decidieron agruparse bajo el nombre "Semilla De Mostaza" en el año 1987. Nombre propuesto por la señora Edita Hurtado en honor a una parábola de la Biblia en la cual se muestra como de un granito de mostaza (que es tan pequeño) crece un árbol inmenso. Así este grupo tan pequeño podría convertirse en una gran obra social para beneficio y satisfacción de sus necesidades y las de otros y otras habitantes del sector. Inspiradas en una vocación de servicio a su comunidad, dieron sentido a su organización y comenzaron a formarse bajo la filosofía de: "equidad de género, solidaridad y fraternidad con el propósito de trabajar por la mujer empobrecida".

La primera iniciativa de este grupo de mujeres se visualizó en la instalación, de una Olla Comunitaria ${ }^{3}$ ubicada en el barrio Marroquín II, que tuvo como meta brindar un servicio de restaurante adaptable a las necesidades de la gente. Inicialmente, las mujeres de Semilla de Mostaza ponían en común los recursos para vivir un día (el diario) y se preparaba una sola olla que alcanzaba para ellas, sus familias y para otras mujeres y familias que tenían necesidad. La preparación de los alimentos lo asumían dos mujeres que se turnaban diariamente. Su encuentro para la preparación de los alimentos generaba un espacio de intercambio de ideas sobre lo que pasaba en su barrio y también para recrear costumbres, generar lazos y fortalecer la amistad.

Hacia el año 1990, el grupo formuló y desarrolló otros proyectos, ahora, con carácter productivo: bordado, panadería y cafetería con financiación del Plan Internacional y otras entidades externas. El 14 de abril de 1992 se convirtió en LA FUNDACIÓN PAZ Y BIEN, como ente jurídico y el 30 de julio del mismo año obtuvo su personería jurídica de la Gobernación del Valle radicada con el No. 0531. El nombre fue escogido por los miembros fundadores, como una síntesis de lo que la Fundación deseaba hacer desde esa entidad. Entre sus miembros fundadores se encontraban el sacerdote Fray Luis Patiño y la Hermana Alba Estela Barreto quienes pertenecen a la comunidad Franciscana y la frase PAZ Y BIEN es el saludo que los Franciscanos heredaron de sus fundadores Francisco y Clara de Asís, siendo a su vez la consigna que identifica a las obras franciscanas en el mundo entero e incluyendo además el ideal de la vida franciscana.

La Fundación Paz y Bien se fundamenta en la organización popular de mujeres, y reúne en torno suyo diversos grupos: La Asociación Semilla de Mostaza, La Olla Comunitaria, Casita de la Vida, La sala Cuna, Jardín comunitario y Educadoras Familiares.

En la actualidad el propósito central de la Fundación es la promoción humana y cristiana de la mujer y de su familia se enfoca en mejorar la calidad de vida de la comunidad, en reducir los índices de violencia, lograr procesos de convivencia pacífica, participación ciudadana y generación de ingresos, dentro de un modelo de economía solidaria en que la persona es respetada. Propósito que se refleja en sus metas como organización, pues son las mujeres como organización social

\footnotetext{
${ }^{2}$ Para mayor información consultar los documentos orientadores de la Fundación Paz y Bien.

${ }^{3}$ La Olla comunitaria implicaba que un grupo de mujeres se hacía cargo de la preparación de los alimentos, con el aporte de mercado de las familias del barrio. De esta olla comían todos los que necesitaran.
} 
las que lideran y gestionan todos los programas que desarrolla la Fundación.

La reflexión en torno a sus valores como mujeres, como seres humanos, como personas con derecho a ser autónomas, libres y capaces de cambiar su realidad las lleva a dar un paso más allá de lo doméstico (privado) y es así como llegan a los Grupos de mujeres por diferentes medios, una amiga, una situación personal difícil, un deseo de conseguir lote para vivienda, compartir con amigas etc. Durante este proceso logran identificar y tener claro que la verdadera motivación era más de fondo, ligada con sus deseos de cambio, superación personal y contribuir al cambio de otras personas: la comunidad.

La experiencia de estas mujeres es reconocida en distintos espacios tanto locales, nacionales e internacionales, otorgándoles un lugar importante por los procesos vividos desde la base.

En este contexto, el argumento central que orientó el trabajo investigativo, es que si bien, estas experiencias se gestan sin un fin político explícito entendido en términos tradicionales ${ }^{4}$, permiten la constitución de sujetos políticos y la manifestación de nuevas formas de hacer política.

\section{LA MUJER COMO SUJETO SOCIAL}

Se concibe sujeto social como aquel que reconoce su papel histórico y la potencialidad que tiene para transformar su realidad en historia política.

En el proceso de constitución como sujetos sociales, las mujeres construyen conciencia sobre su historia de vida y se dan cuenta de toda la potencialidad que tienen para transformarla. Repensar aspectos que han sido importantes en su vida familiar, permite ubicar los momentos desde los cuales inician su preocupación respecto al entorno, al igual, que los momentos en que se empiezan a generar rupturas para dar el salto hacia la constitución como sujetos sociales.

De esta manera, la conciencia respecto a lo que sucede en su entorno, se expresa en distintos aspectos:

El primero, es de orden individual y hace referencia a lo que tienen más próximo y que ha contribuido con la construcción de su subjetividad particular, esto es, la relación con sus padres, hermanos y la conciencia de que están repitiendo los modelos en que se socializaron y la necesidad de buscar otras opciones para no continuar en ese círculo.

El segundo, tiene que ver con los elementos de orden cultural, y socio-económico cuando se reconocen como parte de una diversidad étnica y cultural que trae consigo aspectos muy positivos pero igualmente visualizan condiciones de pobreza, que son producto de las condiciones sociales y económicas del país y que son compartidas por ellas en la cotidianidad:

\footnotetext{
${ }^{4}$ La idea formal de política que se delinea es la de un orden colectivo, de una organización de la convivencia mediante reglas o normas imperativas emanadas del poder que representa la misma colectividad y que impide la disgregación oponiéndose al resurgimiento de conflictos.
} 
"Viendo estas realidades y tomando la mía, que ha sido una vida de dificultades, pero también de alegrías, y convirtiendo los problemas en oportunidades, pues creo que para uno poder valorar la situación tiene que haberle pasado un problema. Eso me ha dado a encontrarme en mi Distrito de Aguablanca, mi gente, los negros, los blancos, los indios, los jóvenes, los adultos, a valorar lo que es la cultura, los credos, las etnias, los sexos también porque para mi tiene mucha significación. Esto me ha dado a meterme un poquito o a conocer cómo vive cada familia, qué es importante para cada persona y por lo tanto sus conflictos son distintos y de distinta manera los resuelven. Entonces, esto me llevó a encontrarme con mi comunidad, poder conocer las diferentes costumbres de cada familia y ganarme la confianza de la gente, comprometerme con ellos, cuando no habia agua, hagamos esto, hagamos aquello, éramos como una familia de cooperar, de participación, de compromiso, de que cuando ellos necesitaran, aqui estoy, ánimo para decir sí podemos y esto fue creando en las personas confianza y credibilidad" (Entrevistada No.2, comuna 14).

La constitución de sujetos reconoce el dinamismo que le imprimen los valores, los elementos socio-culturales, las distintas formas de aprehender la realidad. Es decir, solo en el conocimiento que se hace del proceso donde se articula lo objetivo y lo subjetivo, se pueden producir experiencias que permitan ir perfilando la presencia de estos sujetos.

"La cultura patriarcal, hacia que fuéramos las mujeres las que teníamos que servir a los hombres, entonces, al llegar al grupo, donde lo hacian valorarse como mujer, ese reconocimiento me hizo ir enamorándome más del grupo y con ganas de seguir para aportarle a otras mujeres" (Entrevistada No.1, comuna 14).

El tercero, es de orden económico, y está relacionado con las carencias que afectan a sus familias y la necesidad de salir en la búsqueda de oportunidades que contribuyan en su mejoramiento:

"Un día, la hermana Alba Estela tuvo que viajary conoció una vivencia muy buena en otro país donde existía la "Olla Comunitaria". En el Distrito de Aguablanca todo el tiempo la mujer ha sido como muy marginada, ha dependido de alguien, de un esposo, de un papá, de una mamá pero siempre dependiendo de alguien, y eso queríamos terminarlo. La bermana Alba Estela propuso organizamos y empezar la Olla Comunitaria Nos reunimos 12 mujeres y aportamos la comida que cada una comprabapara su casa” (Entrevistada No. 4, comuna 14.)

Hay un cuarto elemento, que es la vocación de servicio, que es muy explícita en las entrevistas y que subyace en el deseo de vinculación al programa inicial de la Olla Comunitaria y está presente en los proyectos que van surgiendo a partir de esta iniciativa.

La vocación de servicio es motivada por sus creencias religiosas y la presencia de la hermana Alba Stella que las anima a que presten una ayuda a la comunidad en el mejoramiento de sus condiciones de vida lo que se reflejaría además en el mejoramiento de sus familias. 
"Lo que he hecho es mirar la problemática y hacer algo, porque como cristiana tengo que dar mi aporte porque entonces no estaría haciendo nada por el proyecto de Dios" (Entrevistada No. 1, comuna 14).

"Hay una motivación que viene por el lado de la religión, a mi me gusta esa parte, pero no como lo hacian antes, sino la parte social es decir el trabajo comunitario" (Entrevistada No.3, comuna 14).

"Yo todo lo coloco en las manos de Dios, entonces durante el proceso de elección de los Jueces de Paz. dije: Señor si yo soy digna de llegar allápara beneficio de mi comunidad que se haga tu voluntad, Dios mí bendito, que rico poder llegar allá. Dios me da la oportunidad para todo" (Entrevistado. 5, comuna 14).

En el análisis de esta experiencia el reto ha sido identificar a las mujeres como sujetos sociales y políticos tanto en sus manifestaciones presentes como en sus potencialidades e indagar como se expresan en su contexto histórico, como reflexionan su realidad histórica, como la replantean y como se expresan la pluralidad de subjetividades en ese contexto:

'Llevo 19 años de vida comunitaria y empecé con la Hermana Alba Estela nos organizarnos 12 mujeres y empezó la inquietud de cómo nosotras podíamos ser diferentes, ser libres, tener autonomía, seguras de nosotras mismas y de lo que haciamos dentro del ámbito familiar, del matrimonio y de la vida conyugal" (Entrevistada No. 4, comuna 14).

Al pensarse desde su particularidad, las mujeres de Aguablanca, están estableciendo una relación distinta con su entorno buscan influirlo y construir una forma de vida diferente, colocándose, tal vez sin proponérselo, en el lugar de sujetos sociales.

En este sentido, es trascender ese momento en que el individuo se acomoda de forma pragmática a las formas de reproducción de su entorno y se piensa él como responsable de su transformación, es iniciar la conciencia desde su vida en donde el pasado se relaciona con el presente que se vive pero que también pueda brindar otras opciones de futuro convirtiéndose en generador de historia.

Involucrarse en experiencias sociales del barrio les permitió tener una mayor conciencia de su barrio: los problemas de violencia intra familiar, particularmente los problemas de pareja, los niños en situaciones de maltrato, pero también las carencias que en general vivían las personas que habitaban el barrio.

Estas mujeres reconocen que sus búsquedas van más allá de ser madres y esposas que le ayudan a su marido con la subsistencia. Esa búsqueda de crecer como personas y como mujeres así como su interés hacia el servicio a los demás las lleva a contactarse con la Hermana Alba Estela y con personas que comparten sus intereses: 
'Y también con el reconocimiento de cada uno, de cuáles son sus capacidades y hasta dónde puede llegar, porque en el ejercicio de la Consejería sabemos de que yo no reemplazo ni a un abogado, ni reemplazo a un psicólogo, ni reemplazo a una trabajadora social, ni reemplazo al ICBF, ni reemplazo a las Comisarías de Familia, pero sí soy consciente de la problemática que me consultan y sé dónde los puedo remitir. Pero la importancia cuando la persona consulta, usted le hace el recibimiento, el acompañamiento, a escucharlo, porque muchas veces la persona que la consulta no necesita sino como desabogarse, que lo escuchen, entonces todo eso lo trabajamos en la temática" (Entrevistada No.5, comuna 14).

Lo más importante, para ellas, es el reconocimiento que tengan en su papel de consejeras, del valor que les den a sus orientaciones quienes les consultan, mostrar caminos para que las personas hagan sus elecciones y puedan encontrar alternativas frente a sus problemas. Y que además de esto, los programas que han impulsado a partir del proyecto inicial de la "Olla Comunitaria" tenga un reconocimiento no sólo a nivel local sino a nivel nacional:

"La forma en que se expresan y que creen en uno, creen en uno porque si yo no creo en una persona yo no la elijo para las cosas entonces eso me da como para afirmar de que si las mujeres creen en mí cuando hacemos las reuniones, el día de la reunión general están atentas a lo que yo les diga, han depositado su confianza en mí, delegándome cosas que yo puedo bacer entonces cuando uno delega en una persona y confía alguna cosa en otra persona es porque cree en esa persona" (Entrevistada No. 3, comuna 14).

El proyecto colectivo no ha sido algo dado ni instaurado por otros, ha sido una creación colectiva en la cual se han reconocido con historias y orígenes divergentes, y por consiguiente con deseos, valores y necesidades culturales muy amplias. Estas mujeres se han ubicado como seres singulares con una biografía personal, y a su vez participan en la creación de un imaginario social.

Lograr conciencia sobre su entorno, les permite identificar transformaciones que se reflejan en el ámbito privado y en el ámbito público.

Según se ha descrito el proceso de constitución de estas mujeres como sujetos y particularmente como sujetos sociales y políticos ha pasado por la reflexión, tanto, de sí mismas como mujeres, de su relación con el entorno más inmediato como es la familia, como con su relación con el lugar en que viven.

En la reflexión sobre sí mismas, se puede evidenciar el cuestionamiento que hacen sobre su actitud de cómo están asumiendo sus vidas. Se dan cuenta que han actuado como entes pasivos que simplemente reproducen una cotidianidad que las golpea y las estanca y que no hacen algo para transformarla. Ese darse cuenta las lleva a reconocerse como parte de una historia, historia a la cual le pueden imprimir dinamismo para ubicarse como protagonistas generadoras de la misma y no como individuos impulsados sin posibilidades de cambio como hasta ese momento. 


\section{LA MUJER COMO SUJETO POLÍTICO}

Se parte del concepto de sujeto político como aquel que además de tener conciencia histórica actúa buscando la transformación de su realidad.

Los procesos desde los cuales las mujeres transforman su entorno se refiere a las rupturas que se generan en su contexto y que se reflejan en el ámbito privado y en el ámbito público.

Lograr conciencia genera cambios inicialmente a nivel de su entorno familiar que se reflejan en el deseo de propiciar diálogos con la pareja y los hijos para hacerles comprender la importancia de las reuniones con otras mujeres, pues se propician espacios departicipación en la toma de decisiones fundamentales para el bienestar de la comunidad.

Identificar estos cambios las hace redimensionar su papel de consejeras de familia, en el sentido, de querer transmitir a partir de su vivencia las posibilidades de tener una vida familiar más grata y de reconocer en los otros toda la potencialidad que tienen para contribuir a este propósito.

Se puede inferir que una de las transformaciones que se generan en el entorno tiene que ver con los procesos de convivencia y resolución pacífica de los conflictos que estas mujeres propician tanto en el ámbito privado como en el público.

"En este proceso lo principal es uno reconocerse a si misma como mujer, reconocer lo valiosa que es toda mujer, su dignidad, saber que nosotras aprendimos también a valorar al hombre a nivel de la equidad de género, no es que porque somos mujeres y valemos mucho vamos a dominar al hombre, a aplastarlo, no, porque ¿dónde quedaría entonces la familia? Y la familia somos todos, el hombre, la mujer, los hijos... ila meta es aprender a reconocer la dignidad de la mujer, pero que al mismo tiempo la mujer tenga en cuenta y reconozca el valor del varón y en ese reconocimiento en equidad se da la familia"

(Entrevistada No. 2, comuna 14).

Procesos que se ubican claramente en el espacio de la vida cotidiana y que llevan a reconocer el carácter complejo y diverso de la misma, expresado por Agnes Heller (1970) cuando señala que la vida cotidiana es en gran medida heterogénea y ello depende de lo que hagamos y del significado e importancia que le demos a estas actividades. Las cuales están organizadas en torno a la subsistencia, al establecimiento de vínculos, la disposición del territorio, la relación con las instituciones políticas, entre otras, y que generan relaciones de convivencia muy particulares entre los sujetos.

La significación de la vida cotidiana al igual que su contenido también es jerárquica y dinámica, es decir, está en constante transformación y se modifica de modo específico según las diferentes estructuras económico-sociales.

A partir de la descripción de la vida cotidiana podemos identificar los significados que son intercambiados en los procesos de comunicación e interacción, así como los procesos objetivos 
y subjetivos mediante los cuales se construyen y mantienen como válidos dichos significados ${ }^{5}$.

En el caso que nos ocupa, los procesos objetivos se refieren a las distintas formas de organización que asumen estas mujeres como grupo de consejeras, como líderes comunitarias, como integrantes de los grupos parroquiales y los roles que desempeñan al interior de estas, así como, la articulación que se da entre el orden de las instituciones y de la política a lo cotidiano.

De forma complementaria en los procesos subjetivos se identifican las vivencias personales, la manera como sus vivencias han permitido una configuración de la sociedad y de una subjetividad que se concreta en la experiencia sensible de estas mujeres y desde su vocación de servicio buscan soluciones a los distintos problemas que se manifiestan en el barrio con jóvenes, madres adolescentes, desplazados, los niños. etc.

Las acciones que van asumiendo en este contexto de interacciones sociales, nos indican una orientación, un sentido, y el sentido que se puede identificar es, precisamente, hacia una meta de convivencia, en el reconocimiento, elaboración, fortalecimiento y/o transformación de nuestros vínculos interpersonales de tal forma que hagan posible la realización integral de la vida (Arango, 2000: 44)

En su papel de consejeras de familia construyen convivencia, inicialmente por un compromiso personal consigo mismas de no repetir las relaciones que han caracterizado su historia personal y familiar. Y luego con los demás, de reconocerse por la vía del diálogo.

Encuentran que el diálogo permite una conversación donde se aceptan las diferencias y los desacuerdos de manera respetuosa, sin pretender imponer sus ideas y de menospreciar las ideas de los otros. Es por esto que ellas dicen que muestran caminos pero en últimas la persona que les consulta es la que toma la decisión.

A través de estas relaciones dialógicas se reconocen transformaciones concretas, las cuales les van mostrando el alcance de su capacidad para lograr resultados cada vez mejores, tanto en su organización de mujeres como en el impacto de sus acciones en las problemáticas que se viven en el barrio.

En este orden de ideas expuesto, lo que se quiere puntualizar es que en el proceso de constitución como sujeto político las mujeres evidencian transformaciones en las dinámicas de convivencia tanto en lo privado como en lo público. Se identifican transformaciones en el barrio, generadas por ellas como líderes, como sujetos, que ya no solo se cuestionan su ámbito propio (el más próximo) si no que irrumpen en un espacio compartido por otros en el cual esos intereses se encuentran con otros intereses, en este caso por otras mujeres y habitantes de distintos grupos de edad.

${ }^{5}$ El enfoque del interaccionismo simbólico permite clarificar estas construcciones de sentido, para la vida humana y la interpretación de las relaciones sociales que fundamentan la vida cotidiana. 


\section{NUEVAS FORMAS POLÍTICAS CONSTRUIDAS POR LA MUJER}

Las nuevas formas políticas construídas, se refieren a los procesos generados desde las acciones de estas mujeres al margen del Estado y sus instituciones políticas.

En este punto, es donde se considera que su impacto puede mostrar otras formas de concebir lo político, que en términos de Beck se denomina subpolítica:

En el análisis de esta experiencia, si bien es cierto, los elementos que permiten hablar de una forma de subpolítica están referidos principalmente a los espacios de la cotidianidad, su vigor se encuentra en que precisamente permiten replantear la forma de entender la política y el poder, y cuestionan el contenido formal que se le ha atribuído y las formas en que se ejerce este último.

Si la política y el sujeto no se piensan recíprocamente, cualquier proyecto perderá su sentido de transformación profunda y radical. Es por ésto que en el trabajo con los sectores populares se hace necesario replantear el papel de lo subjetivo y la dimensión afectiva implícita en todo proceso de transformación social. Este planteamiento justifica el por qué de la importancia de hablar de sujeto social y político como categorías que se complementan y desde lo cotidiano se expresan de distintas formas. La práctica social siempre estará atravesada por una intencionalidad que se refleja en el cambio o en la acción para la transformación de realidades concretas.

La concepción de lo político se ubica en múltiples espacios, irrumpe y se manifiesta más allá de sus jerarquías formales dando lugar a una reinvención de lo político, hay un inesperado renacimiento de una subjetividad política dentro y fuera de las instituciones, siguiendo a Beck, (1997) lo que en la antigua interpretación de la política se consideraba "retirada apolítica a la vida privada", en el momento actual se interpreta como la lucha por una nueva dimensión de lo político:

'La politica en la casa es como una empresa, donde hay gerente y hay obreros, entonces, como gerentes y obreros tenemos que trabajar conjuntamente para poderla sacar adelante, si la política es algo democrático entonces esto es una forma de hacer política en nuestra casa" (Entrevistada No.1, comuna 14).

Ellas se relacionan dentro de las antiguas formas e instituciones políticas y les hacen el juego, pero también se retiran de ellas, al menos en parte de su valor y compromiso para crear otros espacios de actividad compartida que les permite reconstruir sus identidades.

"En ese momento, me centraba en poder ayudar y conseguir con el Estado muchas más cosas, para poder apoyar y ayudar a la mujer. No me gusta la política, ni me ha gustado. No quiero nada de lo que se trate politicamente. Los jueces de Paz también lo trabajan politicamente, las Juntas de Acción Comunal ya no son las mismas de antes. En este momento tengo una mala imagen, una mala impresión de la política, no volveré a caer en eso" (Entrevistada No.4, comuna 14). 
La acción política de estas mujeres no se ha definido por los espacios de la política formal, tales como los partidos políticos, los sindicatos, los gremios y las instituciones políticas, aunque tampoco es ajeno a ellos. Sus acciones colectivas plantean nuevos espacios en lo privado, lo doméstico y lo comunitario, y formas alternativas con contenido político. El ser reconocidas como consejeras de familia en su barrio, les ha permitido ser jueces de paz, lo que dentro de la visión de la justicia alternativa(o justicia comunitaria), tiene un alto contenido de poder político, pues, su criterio incide en la toma de decisiones con respecto a los procesos de conciliación y de transformación de los conflictos en el ámbito público.

Expresan que no les interesa la política a nivel de instituciones, porque consideran que la competencia es dura. Hay gente muy capacitada y sobre todo los hombres que tienen más experiencia porque históricamente se les ha permitido participar abiertamente de estos espacios.

"Me da susto la forma como se trabaja la política a nivel de instituciones, lo acaban, no lo dejan, y no me siento capacitada para eso. Yo creo que para acceder a un cargo público se debe estar bien preparado para asumir ese reto para asumirse ante esos ogros que están allá y que no saben de qué forma lo van a aprisionar. Las mujeres tenemos que estar bien fortalecidas. Si una de las mujeres llega acceder a un cargo público e incidir en el manejo del país, tiene que hacerlo bien, para no repetir las mismas historias de los que han hecho y han manejado el país" (Entrevistada No. 1, comuna 14).

Sin embargo, a partir de su labor de consejeras, han logrado obtener por elección popular la participación en cargos como comuneras en las Juntas Administradoras Locales, ser juezas de paz y tener presencia en todos los espacios que se convocan colectivamente en el barrio. Sus aspiraciones, aunque muy tímidamente lo expresan, son poder asumir con mayor fuerza espacios en los cuales puedan tomar decisiones, manejar recursos y que cada vez haya un mejoramiento de las condiciones de vida de la población.

"Son saltos que se van llevando y cuando ya caminamos, la gente lo conocen a uno como obra o como actúa, vamos donde fulana o perencejo y entonces yo estoy segura que esos 100 votos que las personas me dieron para Jueza de Paz demuestran la confianza de la gente. Cien personas es un buen grupo que me apoya y cree en mi por eso pienso que si sirvo para algo" (Entrevistada No. 2, comuna 14).

En su constitución como sujetos sociales y políticos, han aprendido a reconocer quiénes quieren utilizarlas para beneficio propio, saben que son importantes y que manejan poder en su barrio que les permite movilizar a la población, en tal sentido, son críticas frente a los que pretenden envolverlas en esa red clientelista que caracteriza a ciertos líderes politiqueros que se mueven en el barrio:

"No pude saber como supo el señor que yo me llamaba Doris Campos, tenía mi teléfono y no pude descubrirlo, pero me llamaba, me insistía y yo le dije no. soy Jueza de Pazpero nada de política. El señor insistió hasta que un día mi esposo le dijo: no cuente con ella porque ella no va a ir. Pienso ellos 
lo pueden hacer porque como saben que uno es reconocido en el ámbito donde uno se mueve buscan la oportunidad, y lo quieren utilizar como un gancho, como un anzuelo para que la gente vote por esa persona"(Entrevistada No. 5, comuna 14).

Son críticas, respecto a esas formas tradicionales en las que se ha manifestado el ejercicio de la política, por ejemplo, el que siempre se les mire como potencial electoral y lleguen los políticos a prometer muchas cosas que finalmente no cumplen, porque lo que realmente se hace es un mal negocio en el cual se da un voto, pero siempre se quedan esperando que va pasar:

"Yo de eso sé muy poco... pero lo único que le se decir es que la gente con una muñeca, o con un bulto de cemento se deja llevar. Claro que ahora han despertado mucho pero si les dicen que les dan tres metros de arena, corren y van a reuniones. Pienso que la gente está mal informada o no tiene un criterio verdadero, uno no es un objeto para que lo busquen solamente para las elecciones y después qué. Ayer una señora que es líder quería saber donde estaba el señor que había salido para el Senado y que le habia prometido a las madres cabezas de hogar una ayuda con el Plan Colombia entonces dije yo, vaya pues donde lo va a localizar si cuando estaba en la política tenía su sede aqui en Caliy aborita ya no sabemos, está en Bogotá ese es el error tan grande de que uno se presta para todo eso y después dejan a la gente triste porque la señora según me manifestaba necesitaba trabajo y se aprovechan para engañar, y yo con eso si no estoy de acuerdo porque uno debe ser sincero y honesto" (Entrevistada No. 5, comuna 14).

La política es vista como algo negativo porque en el fondo significa abuso del poder:

'Porque se ve mucha corrupción, cosas injustas, que no van en equidady aún más se ve que la mujer en realidad es totalmente discriminada y desplazada dentro de la misma politica. Entonces no me ha gustado, pero en ese momento teníamos que estar involucradas y meternos un poquito en ese cuento, no podiamos pasar eso desapercibido y lo hicimos y yo me metí muy de lleno a eso... dentro de la misma JAL observé la corrupción, de los funcionarios de la Alcaldía, de la Gobernación y eso hay que saberlo manejar uno de mujer... y otra cosa que hay dentro del mismo ámbito político cuando la mujerpopular, la mujer de sectores como el Distrito de Aguablanca siempre la miran como una persona, a ver, como le explico, la ven como a esa persona que se puede manejar tal vez. seduciéndola, tal vez diciéndole cosas bonitas al oído" (Entrevistada No. 4, comuna 14).

Como mujeres piensan que pueden y se atreven a competir para lograr una acción política que se salga de lo tradicional:

'Dentro de ese proceso, desde hace 8 años, nosotros y la hermana Alba Estela y las mujeres empezamos a decir: es que la mujer debe estar involucrada en la politica, entonces abi fue donde se tomó la decisión de sacar una candidata para la Junta Administradora Local (JAL), como Comunera. Se bizo una elección y la verdad todas me apoyaron, todas dijeron, que sea doña Alicia la candidata y todas la vamos 
apoyary la verdad que lo logramos porque sacamos la primera votación en toda la Comuna 14, saqué 1090 votos en ese entonces y por lo tanto quedé como Presidenta de la J AL por haber sacado la más alta votación” (Entrevistada No. 4, comuna 14).

En este sentido, cuestionan el ejercicio del poder de sus dirigentes en el barrio:

"Es que por el sector donde vivo, han hecho dos elefantes grandototes que han sido el Cali 15 que lo montaron se robaron miles de millones de pesos pero no lo terminaron. Y también bicieron el Colegio, primero fué una galería pero luego lo convirtieron en un colegio y resulta que eso ya está dotado y abí invirtieron miles de millones de pesos y no se vió lo realmente invertido, pero nosotros como comunidad como nunca nos preocupamos por el bienestar de lo que está ahi entonces por eso hacen lo que hacen"

(Entrevistada No.5, comuna 14).

Con base en los planteamientos de Beck (1997) la ciencia política ha abierto y elaborado su concepto de lo político en tres aspectos: la constitución institucional de la comunidad política con la que la sociedad se organiza así misma, los programas políticos, y los procesos de conflictos políticos relativos al reparto del poder, desde aquí el individuo no se considera adecuado para la política, sino que el núcleo central lo constituyen los agentes colectivos.

Por su parte, el análisis de la subpolítica le da un lugar a ese sujeto que la política está excluyendo, de igual manera, a otros actores: las iniciativas ciudadanas, la opinión pública, los líderes comunitarios, etc, en el creciente poder configurador de lo político ${ }^{6}$. Por lo tanto la subpolítica significa configurar la sociedad desde abajo y en este sentido, es que se considera que lo que han hecho las mujeres de Aguablanca da indicios de subpolítica, pues a través del proceso vivido en su barrio han tenido voz y participación en la organización de su cotidianidad y cada vez ganan más espacio en la configuración de lo político.

\section{CONCLUSIONES}

La experiencia de estas mujeres del Distrito de Aguablanca se constituye en una de esas formas alternativas que permiten hablar de la construcción de la sociedad desde abajo y en este proceso se manifiestan como sujetos, en la medida en que cuestionan su entorno, cuestionan el papel que les ha asignado la cultura: ser amas de casa, preocupadas por atender a sus hijos, de las labores domésticas y dependientes de sus esposos. Cuestionan además sus condiciones económicas precarias y la posibilidad de jugar un papel protagónico en la transformación de las mismas.

Sentirse reconocidas como líderes, les ha permitido avanzar en ese proceso de constitución como sujeto, es el aporte que le hacen los otros a la construcción de su identidad y la relación que

\footnotetext{
${ }^{6}$ Beck traslada la distinción entre la política y la subpolítica, a la investigación de las prácticas de la modernidad cuya estructura cambia de múltiples formas, en este sentido la coloca como consecuencia de la modernidad reflexiva.
} 
se genera entre subjetividades. El proyecto que les ha permitido agruparse no ha sido algo dado ni instaurado por otros, ha sido una creación colectiva en la cual se han reconocido con historias y orígenes divergentes, y por consiguiente con deseos, valores y necesidades culturales muy amplias.

Estas mujeres se han ubicado como seres singulares con una biografía personal, que a su vez participan en la creación de un imaginario social.

Como se señaló anteriormente, uno de los hallazgos más importantes en términos de transformación del entorno que logran las mujeres entrevistadas es generar formas alternativas para la resolución de conflictos, las cuales han tenido incidencia en las relaciones de convivencia familiar y comunitaria.

Es así como, estas transformaciones se evidencian en los siguientes logros:

- El reconocimiento de la comunidad del papel que desempeñan en la resolución alternativa de conflictos. Sustentado en la conciliación de más del 50\% de los conflictos que atienden en la comunidad y de manera formal en la casa de Justicia.

- La existencia de más de 140 consejeras de familia en una gran red organizativa en el Distrito de Aguablanca.

- Cuatro consejeras electas juezas de paz.

- Invitación a llevar el programa a diez municipios del Valle

- Disminución de la violencia familiar.

Esto es de resaltar, si se tiene en cuenta que en Colombia el fenómeno de la violencia ha llevado a que se ubique a nuestro país entre los países más violentos del mundo. Sobre la base de los datos estadísticos, se dice que la violencia en Colombia tiene un carácter estructural y se lanzan peligrosas generalizaciones que sostienen la hipótesis de que pertenecemos a una "Cultura de la Violencia". Y apoyados en esto, distintos actores institucionales impulsan múltiples esfuerzos por crear condiciones para trascender a una "Cultura de la convivencia pacífica".

En este sentido, los procesos de convivencia generados por las mujeres cobran mucho valor, además, porque surgen por fuera de la institucionalidad del Estado, son iniciativas que se van dando desde sí mismas y producen relaciones de reconocimiento, aceptación, intercambio, encuentro, compromiso y fortalecimiento de los vínculos personales y comunitarios.

Hoy día, todos los candidatos políticos aspirantes a los cargos públicos, tanto municipales como nacionales, desde su discursos, resaltan la importancia de elaborar propuestas de paz en términos esencialmente de crear condiciones para resolver los conflictos de manera pacífica y disminuir la utilización de formas violentas; y no se dan cuenta que explícita o implícitamente las instituciones políticas existentes están abandonando o recortando su papel en lo referido a atender las demandas de los individuos en cuanto a sus carencias materiales y reivindicación de derechos. Y la búsqueda de mantener el rol tradicional desempeñado por el Estado para legitimar, promover, instalar y hacer cumplir cualquier conjunto de valores se va desplazando por formas alternativas que se gestan desde los individuos. 
El rechazo a lo que tradicionalmente se considera como política por sus connotaciones de politiquería y corrupción, es un factor que favorece la organización de los sujetos sociales y políticos a favor de la auto-gestión y del desarrollo de proyectos con fines productivos en beneficio de la comunidad.

Este rechazo a la idea tradicional de lo político hace que las personas como sujetos sociales se organicen y actúen, aunque inicialmente, no se den cuenta que esta es una forma de hacer política, según sus reflexiones.

La nueva visión de la política (subpolítica) muestra cómo es posible proponer una relación diferente entre lo público y lo privado, pues, su relación es mutua e interdependiente más allá de la separación artificial de lo público como algo externo a los sujetos sociales.

\section{REFERNECIAS BIBLIOGRÁFICAS}

ARANGO, CALA CARLOS y CAMPO, SARRIA DANIEL(2000) "Educación para la convivencia en contextos comunitarios". Informe final de investigación: Construcción participativa de la convivencia en un barrio popular de Cali. Universidad del Valle. Escuela de Psicología.

BECK, ELIZABETH; BUTLER JUDITH y PUIGVERT LIDIA(2001) Mijeres y transformaciones sociales Barcelona.

Editorial Roure.

BECK, ULRICH(1994) Modernización reflexiva: política, tradición y estética en el orden social moderno. Madrid. Alianza Universidad.

BECK, UlRiCH (2002) La sociedad del riesgo global. España. Siglo Veintiuno de España Editores. BONETE, PERALES ENRIQUE (1995) La faz oculta de la modernidad. Madrid. Editoriales Tecnos. Bobbio, norberto y Bovero, michelangelo (1991) Origen y fundamentos del poder político México.

Ediciones. Grijalbo

FERNANDEZ, LIDIA (1997) "Subjetividades emergentes, psiquismo y proyecto colectivo" en Subjetividad:

Umbrales del pensamiento social. México. Ediciones Antropos.

GIDDENS, ANTHONY; Z. BAUMAN y N. LUHMANN, y U. BECK (1996) Las consecuencias perversas de la modernidad. México. Ediciones Antropos.

GUERRA, RODRIGUEZ CARLOS (1997) "Hacia una sociología del sujeto: Democracia y sociedad civil" en Subjetividad: Umbrales del pensamiento social. México. Ediciones Antropos.

HÉLLER, AGNES (1997) Sociología de la vida cotidiana. Barcelona. Ediciones Península, HÉLLER, AGNES (1990) Historia y futuro, jSobrevivirá la modernidad! Barcelona. Ediciones Península. INSTITUTO POPULAR DE CAPACITACIÓN (1995) Solución de conflictos. Medellín. R.J Lecturas.

MELUCCI, ALBERTO (2001) Vivencia y convivencia. Teoría social para una era de la información. Madrid.

Editorial Trotta.

MOLYNEUX, MAXINE (2003) Movimientos de mujeres en América Latina. Estudio teórico comparado. Madrid.

Ediciones Cátedra.

RACHJMAN, JOHN (2001) Lacan, Foucault y la cuestión de la ética. México. Ediciones Pe ele.

SARTORI, GIOVANni (1998) Política lógica y método en las ciencias sociales México. Fondo de Cultura Económica. TORRES, CARRILLO ALFONSO (1999) Movimientos sociales y organización popular. Bogotá. Universidad

Pedagógica Nacional.

TORRES, ALFONSO (1996) Discursos prácticas y actores de la educación popular en Colombia durante la década de

los ochenta. Bogotá. Universidad Pedagógica Nacional.

TORRES, ALFONSO (2000) "Subjetividad y sujetos sociales en la obra de Hugo Zemmelman", Folios,

Revista de la Facultad de Humanidades de la Universidad Pedagógica Nacional, Bogotá. pag 18. TOURAINE, ALAIN (1997) ¿Podremos vivir juntos? Bogotá. Fondo de Cultura Económica. 
TOURAine, Alain (2000) Crítica de la modernidad. Bogotá. Fondo de Cultura Económica.

TOURAine, ALAin (2002) A la búsqueda de sí mismo: Diálogo sobre el sujeto. Barcelona. Ediciones Paidós.

VARELA, BARRIOS EDGAR (1998) Desafíos del interés público: identidades y diferencias entre lo público y lo privado.

Cali. Editorial Universidad del Valle.

Zemmelman, Hugo (1995) Determinismos y alternativas en las ciencias sociales de América. Latina. México.

Ediciones nueva sociedad.

Zemmelman, hugo (1996) Problemas antropológicos y utópicos del conocimiento. México. Jornadas

ZEMmelman, HUGo y LEÓN, EMma (1997) Subjetividad: umbrales del pensamiento social, México. Editorial el Hombre.

ZEMMELMAN, HUGO (1992) Los horizontes de la razón dialéctica y apropiación del presente I. México. Editorial el hombre.

ZEMmelman, HUGO (1998) Los horizontes de la razón historia y necesidad de utopía II. México. Editorial El hombre.

Zemmelman, hugo (1998) Sujeto, existencia y potencia. México. Editorial Antrophos.

Recibido en junio 15 de 2004

Aprobado en agosto 23 de 2004 